\title{
Por Igual Más: una vidriera para exhibir la diversidad
}

\author{
Por Igual Más: a window to exhibit the \\ diversity
}

\section{Palabras clave:}

Personas con discapacidad, inclusión social, diversidad, aceptación de la diferencia, discriminación, Por Igual Más.

\section{Keywords:}

People with disabilities, social inclusion, diversity, acceptance of difference, discrimination, Por Igual Más.

\section{1. ¿Qué vemos cuando vemos?}

Vidrieras que exhiben maniquíes con cuerpos esbeltos, curvados, diminutos, que responden a la actual lógica del mercado: vender un estereotipo de lo que debe ser aunque eso contradiga la real-realidad. Eso es lo que en cualquier parte del mundo se repite en cada tienda y se difunde a través de los medios de comunicación. No importa la nacionalidad de los maniquíes, pareciera que todos son fabricados por la misma mano; y en parte así lo es. Las leyes del capitalismo y los valores que éstas instauran, producen en masa muñecos que presumen ser perfectos. La belleza, en ese sentido, también queda sujeta a las exigencias de la oferta y sólo se la evalúa a partir de una mirada exteriorcéntrica.

Sin embargo, es necesario preguntarnos: ¿Quién tiene un cuerpo perfecto? ¿Quién puede ser llamado perfecto? ¿Quién determina los parámetros de perfección para saber qué es lo que se debe ser, hacer, decir? Estas preguntas se me presentaron a partir de la campaña contra la discriminación que la organización suiza Pro Infirmis "puso en vidriera"

I. Pro Infirmis "Because who is perfect?" dirigido por Alain Gsponer ‘http://www.youtube.com/ watch?v=E8umFV6 $9 \mathrm{fNg}$.

\section{Ana Argento Nasser <aniargenas@gmail.com〉 \\ Fundadora de Por Igual Más}

Para citar:

Argento Nasser, A. (20I4): "Por Igual Más: una vidriera para exhibir la diversidad", Revista Española de Discapacidad, 2 (2): 26I-267.

$<$ http://dx.doi.org/I0.5569/23405104.02.02.I6> 
Con una acción clara y concreta evidenció el poco pluralismo que existe en la moda: creó maniquíes inspirados en personas con discapacidad que fueron realizados con las medidas reales de personas con escoliosis y con miembros amputados que accedieron voluntariamente a que se replicara su figura, y los exhibió en una calle principal del centro de Zúrich, Suiza.

A pesar de la rápida lectura que podemos hacer del video que Pro Infirmis subió a YouTube (y que ya ha sido visitado por cerca de diez millones de personas de diferentes partes del mundo y subtitulado a diferentes idiomas), es importante detenerse en la profundidad del mensaje, en las imágenes y en las interacciones que se producen.

En primer lugar, la persona que lleva adelante la campaña comparte un momento con los protagonistas: las personas con discapacidad. Les pregunta, les conoce. No es indiferente a lo que desean, les da la posibilidad de tener voz propia.

Al mismo tiempo, les devuelve la dignidad de personas, de ser sujetos de derechos, de ser visibles socialmente. Y así les permite poder ser también modelos de belleza y mirarse a sí mismos como los otros los miran o los podrían mirar.

En ese sentido, el mensaje es una gran apuesta a la diversidad e inclusión y permite observar cómo cuesta aceptar la diversidad como una necesidad social. Y en este punto, una de las principales barreras son la comunicación y la educación. Por ello no sorprende que quiénes se detienen frente a la vidriera ante la sorpresa de los nuevos modelos extraños, expresen su negación a la diferencia exhibida. Todavía no estamos sensibilizados socialmente para lograr romper con el molde fordista de la perfección.

Así, podemos ser transeúntes de la calle Bahnhofstrasse de Zúrich o de la calle Corrientes de la Córdoba del país "del fin del mundo" -como llamó el Papa Francisco a Argentina- y el impacto va a ser el mismo porque nuestra forma de mirar al otro no está educada en la diversidad y esa es una materia social pendiente.

\section{Del modelo social al comunicacional y de reconocimiento legítimo de la discapacidad}

Este fenómeno de exclusión ha sido analizado por numerosos autores. Muchos de quienes se especializaron en la discapacidad, investigaron esta fragmentación social a partir de diferentes modelos. De esta manera, explicaron que la discapacidad se fue construyendo a lo largo de la historia a través del modelo de la prescindencia, el rehabilitador y el social ${ }^{2}$.

Según el modelo de la prescindencia (Palacios y Romañach, 2006), la persona con discapacidad debía ser "desechable" porque poseía un castigo divino, el de ser diferente, el de ser discapacitado. Se supone que las causas "de ser discapacitado" tienen un motivo religioso, en el que las mujeres y hombres con este tipo de diferencias se consideran innecesarias por diferentes razones: porque se estima que no contribuyen a las necesidades de la comunidad, porque albergan mensajes diabólicos, porque son la consecuencia del enojo de los dioses, o porque sus vidas no valen la pena para ser vividas. Como consecuencia de estas premisas, la sociedad decide prescindir de las mujeres y hombres con discapacidad ya sea a través de la aplicación de políticas eugenésicas o ya sea situándolas en el espacio destinado para los "anormales" y las clases pobres. Ello con un denominador común marcado por la dependencia y el sometimiento, en el que asimismo son tratadas como objeto de caridad y sujetos de asistencia.

Por su parte, el modelo rehabilitador entiende a la discapacidad como una enfermedad que se debe curar. Se termina, prácticamente,

2. Si bien pueden ser conocidos por gran parte de los lectores, considero importante citar una breve síntesis de cada uno para poder, al final, proponer una mirada diferente. 
medicalizando la vida y se pone énfasis en el "déficit" de la persona, que es su discapacidad. Esta es una visión asistencialista y excluyente ya que entiende que la discapacidad es propia sólo de la persona que la posee. Desde su filosofía, se considera que las causas que originan la discapacidad no son religiosas, sino científicas. Por ello, desde este modelo, las personas ya no son consideradas inútiles en la medida en que sean "rehabilitadas". De esta manera, el fin primordial que se persigue es "normalizar" a las mujeres y hombres que "son diferentes", aunque ello implique forzar a la desaparición o al ocultamiento de la diferencia que representa la discapacidad. Así, el éxito es valorado en relación con la cantidad de destrezas y habilidades que logre adquirir el individuo como consecuencia de la rehabilitación (Palacios y Romañach, 2006).

Por último, el modelo social entiende que la discapacidad es una "construcción social" ya que si, por ejemplo, se hubieran diseñado las ciudades pensando en las personas con discapacidad, éstas no se sentirían impedidas para desarrollarse y desenvolverse autónomamente. Al mismo tiempo, considera que las causas que originan la discapacidad no son ni religiosas, ni científicas, sino que son sociales; y que las personas que la poseen pueden aportar a las necesidades de la comunidad en igual medida que el resto de mujeres y hombres, pero siempre desde la valoración y el respeto de su condición de personas diferentes. Este modelo se encuentra íntimamente relacionado con la incorporación de ciertos valores intrínsecos a los derechos humanos, y aspira a potenciar el respeto por la dignidad humana, la igualdad y la libertad personal, propiciando la inclusión social y sentándose sobre la base de determinados principios: vida independiente, no discriminación, accesibilidad universal, normalización del entorno y diálogo civil, entre otros. Además, se parte de la premisa de que la discapacidad es una construcción y un modo de opresión social y el resultado de una sociedad que no considera ni tiene presente a las mujeres y hombres con alguna limitación funcional. Asimismo, reivindica la autonomía de estas personas para decidir sobre su propia vida y, para ello, se centra en la eliminación de cualquier tipo de barrera, con el fin de brindar un adecuado equilibrio de oportunidades (Palacios y Romañach, 2006).

Por lo tanto, el problema no es la discapacidad presentada por la persona, sino que son las estructuras, prácticas y actitudes las que impiden a las personas desarrollar su potencial. Mientras que frecuentemente el modelo médico se ha caracterizado por ubicar el llamado "problema" dentro de la persona, el modelo social ubica el problema de la discapacidad en el ambiente. Es el ambiente, el entorno social, el que no logra asegurar un espacio de acción y desarrollo para las personas con discapacidad. (Palacios y Romañach, 2006)

Así, el modelo social de la discapacidad apunta a explicar, por ejemplo, que una persona sorda no ve la televisión ni asiste a conferencias debido a la falta de subtítulos o interpretación en lenguaje de signos, y no por su discapacidad auditiva.

He aquí que quiero proponer un modelo que surge del modelo social y que considero que puede contribuir a complementarlo. Si bien el modelo social es, a mi criterio, superador de los otros dos primeros y responde a las demandas de las personas con discapacidad, sin embargo es tan amplio que algunos puntos específicos, de los cuales pueden realizarse prácticas concretas, podrían quedar relegados. Me refiero a poder pensar el lenguaje como constructor de realidades y, por lo tanto, a la comunicación como posibilitadora del reconocimiento del otro como sujeto de derechos. En ese sentido, el modelo comunicacional y de reconocimiento legítimo de la discapacidad pretende dar un paso más allá: no sólo es necesario que la sociedad reconozca los derechos de las personas con discapacidad, es también importante que las mismas personas reconozcan su situación, se organicen y luchen por su dignidad dentro de las sociedades democráticas que -al menos discursivamenteregulan mediante leyes lo que debería ser cumplido para lograr una sociedad más justa.

Para fundamentar este viraje, es necesario pensar en teorías sobre el reconocimiento de 
grupos vulnerados y sus luchas presentes a nivel discursivo.

Axel Honneth ${ }^{3}$ es quien más ha profundizado, con propósitos teóricos desde una reflexión crítica, en la cuestión de las formas de reconocimiento a partir de la Teoría Crítica. Sus planteamientos en la Teoría de la Lucha por el Reconocimiento o Teoría del Reconocimiento Recíproco (Honnett, I997) son muy útiles a la hora de elaborar una interpretación crítica de las formas de reconocimiento ideológico ("promesa evaluativa", a nivel discursivo) y de reconocimiento legítimo ("evaluación material”, la cristalización o materialización de esa promesa) que pueden socialmente aparecer hacia las personas con discapacidad. Esto es fundamental dentro de las sociedades democráticas, reguladas por leyes que prometen una mejor calidad de vida para los grupos excluidos pero que -al menos en Argentinamuchas de ellas quedan sólo en la promesa discursiva y no en su aplicación. Es el caso, por ejemplo, de la Convención Internacional de los Derechos de las Personas con Discapacidad (ONU, 2006), en línea con las tesis del modelo social, relegada por los Estados que se adhirieron a ella al no materializar sus correspondientes preceptos.

Por otra parte, la Teoría del Reconocimiento postula que el reconocimiento implica no sólo la comunicación lingüística (una de las seis dimensiones más importantes por medio de la cual los sujetos mantienen sus vínculos vitales en su vida cotidiana), sino la comunicación desde un sentido racional y moral, la cual se lleva a cabo en la interacción intersubjetiva orientada hacia un fin común. Esta interacción sería decisiva en la lucha de los sujetos por la emancipación, dado que mediante la comunicación, las personas con discapacidad pueden constituirse como una voz autónoma por

3. Profesor, Doctor, filósofo y sociólogo alemán. Desde el año 200 I es director del Instituto de Investigación Social (Institut für Sozialforschung) de la Universidad de Frankfurt. Desde el año 2007 es presidente de la Asociación Internacional Hegel (Internationale Hegel-Vereinigung). Es co-editor de la revistas Deutschen Zeitschrift für Philosophie, European Journal of Philosophy y Constelaciones. la que reclamen ser reconocidas legítimamente como ciudadanos de derechos y valores en la actual sociedad democrática. (Honneth, I997).

De este modo, la comunicación representa su aspiración de ser reconocidas socialmente, es decir, sus luchas moralmente motivadas para ser reconocidas ideológica y legítimamente como ciudadanas dignas de derechos y valores. Esto conduciría a generar una transformación social consensuada, lo que contribuiría a generar el auto-respeto, la auto-estima y la auto-confianza de estos grupos sociales.

\section{Por Igual Más: sumando ecos de inclusión y diversidad}

Ante la necesidad de aproximarse, de acercarse a aquellas personas que son excluidas por la imposibilidad social de aceptar la diferencia, ante la urgencia de darles voz y, en fin, de reconocerlos no sólo discursivamente sino también legítimamente, surgió Por Igual Más. Este sueño, que hoy ya es una Fundación, nació con otro nombre a fines del año 2009: "Cultura para Todos: Proyecto de Inclusión Social”. En el año 2008, cuando cursaba segundo año de la carrera de Comunicación Social, ingresé como pasante en el Museo Histórico del Colegio Nacional de Monserrat. Un día, unas estudiantes de Turismo me preguntaron con qué recursos contábamos en materia de Turismo Accesible. Yo ni siquiera sabía qué significaba eso y no me gustó responderles: "Nada”. Entonces pensé “¿Qué puedo hacer yo para cambiar esta situación?”. Así, puse manos a la obra: escribí un proyecto que fue aprobado por el Director del museo y reuní a personas especializadas en otras áreas diferentes a la comunicación para que trabajáramos juntas. Antes de llevarlo a cabo, contactamos con referentes de algunas instituciones vinculadas a la discapacidad y con personas con diferentes discapacidades, para consultarles qué les parecía la propuesta y cómo podríamos mejorarla. El intercambio de conocimientos fue muy útil y necesario para 
tener la certeza de que lo que íbamos a hacer respondería realmente a las necesidades de inclusión que teníamos como meta.

A partir de ahí, hicimos videos subtitulados para personas sordas, folletos con letra en macrotipo para personas con dificultades visuales, se instaló una rampa móvil, las guías aprendimos la lengua de signos y fuimos asesoradas para el trato con personas con discapacidad por el Equipo Técnico Accesible dependiente del Ministerio de Desarrollo Social de la Provincia de Córdoba. Al mismo tiempo, el profesor Aldo Ceballos, que es ciego, transcribió toda la cartelera del museo al Braille, y él me enseñó ese sistema de comunicación.

Una vez que habíamos alcanzado el objetivo de posibilitar que las diferentes personas con discapacidad pudieran acceder a las muestras del museo e interactuar con ellas, hicimos una prueba piloto donde invitamos a diferentes colegios de niños y de jóvenes con discapacidad. La experiencia fue muy gratificante.

Posteriormente, mi intención fue expandir el trabajo. Entonces me presenté junto con un equipo interdisciplinario a las becas de extensión que la Universidad otorgaba. Gracias a que obtuvimos una, pudimos replicar el proyecto en tres museos ${ }^{4}$ más de la Universidad Nacional de Córdoba (Argentina): el Museo Casa de la Reforma, el Museo del Observatorio y el Museo Científico Tecnológico. La propuesta se llamó "Cultura para Todos: Proyecto de Inclusión Social”.

Al mismo tiempo, relevamos todos los otros museos de la universidad que no habían podido entrar dentro de la beca y elaboramos

4. Distintas Facultades de la Universidad Nacional de Córdoba y otros centros pertenecientes a ella han creado a lo largo de la historia de la UNC dieciséis museos universitarios que exhiben distintos tipos de muestras. Los Museos son: Museo del Colegio Nacional del Monserrat, Museo Histórico de la Universidad Nacional de Córdoba, Museo Histórico de la Facultad de Derecho, Museo de Botánica, Museo de Mineralogía, Museo de Zoología, Museo de Paleontología, Museo de la Casa de la Reforma, Museo de Anatomía Patológica, Museo Anatómico "Pedro Ara”, Museo de Antropología, Museo Científico Tecnológico, Museo del Observatorio, Museo Virtual de Arquitectura, Museo en Ciencias de la Salud. un diagnóstico para cada uno, así como la descripción de las acciones concretas que podrían desarrollar con el fin de que contaran con las herramientas necesarias para ejecutar un plan de accesibilidad e inclusión. Este material fue entregado a cada Director en formato digital.

Al finalizar el año 2009, para compartir la experiencia del proyecto en los museos, hice un blog que fue sumando visitas ${ }^{5}$. Con el tiempo éste era visitado y recibía cada vez más consultas, por lo que entendí que era necesario hacer un viraje. Así, en el año 20ro el blog cambió de nombre (se comenzó a llamar "Por Igual Más” ${ }^{6}$ ) y, junto con ello, el diseño de la página. La iniciativa tenía por motivo reflejar no sólo el proyecto en los museos, sino también la accesibilidad e inclusión social en general. A pesar de todos estos cambios, los objetivos siguieron siendo los mismos: vehiculizar información para dar visibilidad a las personas con discapacidad.

Posteriormente, a mediados de 2012, inmersos en un mundo interconectado y sensibles a la importancia que las redes sociales tienen en la creación de "e-vínculos”, Por Igual Más cambió nuevamente su aspecto y junto con esa transformación, también amplió sus objetivos: convertirse en un espacio de encuentro para las personas con discapacidad, sus familias, las instituciones vinculadas con la inclusión y la accesibilidad y la sociedad en su conjunto. Para ello, agregamos nuevas herramientas a la página (encuestas, bloque de comentarios, la sección "Comunidad" que permitía enviar correos a una dirección creada para tal fin, entre otros).

En enero de 20I3, el proyecto fue reconocido por la ONU-HÁBITAT como Good Practise ${ }^{7}$.

5. El dominio del blog era «www.culturaparatodosmuseosunc. blogspot.com?.

6. Al mismo tiempo, se adoptó un dominio diferente: ‘www. porigual.com.ar'.

7. ONU HÁBITAT realiza anualmente una convocatoria sobre Buenas Prácticas para elegir "The Best Practise". La distinción reconoce a las acciones o iniciativas que mejoran el entorno y el modo de vida. Los siguientes links detallan el reconocimiento: ‘http://habitat.aq.upm.es/bpal/onu I 2/bp4368.html http://www.porigual.com.ar/2013/oI/reconocimiento-porigual-y-cultura-para.html. 
Ese reconocimiento fue el motor para seguir trabajando y creando nuevos proyectos en pos de la inclusión de las personas con discapacidad. A partir de allí comencé la búsqueda para tejer alianzas estratégicas con fundaciones, organizaciones y empresas, con el fin de poder efectuar acciones concretas. La recomendación fue que Por Igual Más tenía que dejar de ser sólo un proyecto para institucionalizarse en una Fundación.

A fines de 2013, cuando muchos estaban cerrando el año, Por Igual Más estaba abriendo caminos, empezando una nueva etapa y moviéndose en pos de un sueño: ser un canal útil para la inclusión de las personas con discapacidad.

En enero de 20I4 tuvimos nuestra primera reunión con las personas que conformarían la Fundación y desde entonces estamos día a día trabajando para brindar servicios de consultoría gratuita a las familias de las personas con discapacidad. También nos hemos comprometido con la producción y realización de micro radiales y audiovisuales que ayuden a concienciar a toda la sociedad, así como en la constante vinculación con la comunidad, respondiendo a sus inquietudes y aportando a la igualdad de oportunidades.

Otro de nuestros objetivos es realizar y actualizar una base de datos con las diferentes instituciones que presten servicios en materia de discapacidad en Argentina, para facilitar la tarea de búsqueda a las personas con discapacidad y a sus familias. Por otro lado, estamos trabajando en la confección de un glosario con las diferentes discapacidades y algunas de las enfermedades discapacitantes, y en la realización de una agenda con las distintas instituciones educativas (en sus diferentes niveles: inicial, primario y secundario) que brinden educación al alumnado con discapacidad.

Al mismo tiempo, mudamos la plataforma web del sitio para ofrecer una página accesible y coherente con nuestra misión. Por ello, desde el año 20I4, Por Igual Más es una red social ${ }^{8}$. Estamos convencidos de que dar voz es una forma de reconocer los derechos y la dignidad de cualquier persona. Por ello abrimos caminos a esta forma de interrelacionarse en la web, para que toda persona interesada en la temática se pueda sumar al proyecto a través de las distintas vías que la red social ofrece: compartir contenidos, experiencias, reflexiones y consejos.

Así, poco a poco pero con paso firme, desde Por Igual Más trabajamos para que cada vez sean más las vidrieras (las de moda, de productos, de miradas, del lenguaje; en fin, de la cultura) que exhiban la diversidad y la inclusión social del otro, del diferente, del que sólo necesita de posibilidades reales de ser, estar y hacer para tener un verdadero reconocimiento.
8. El dominio de la actual red social es ‘www.porigualmas. org. 


\section{Referencias bibliográficas}

Honneth, A. (I997): La lucha por el reconocimiento. Por una gramática moral de los conflictos sociales, Barcelona: Crítica.

ONU (2006): Convención sobre los derechos de las personas con discapacidad, Nueva York: Naciones Unidas (en línea). <http://www.un.org/ esa/socdev/enable/documents/tccconvs.pdf>.
Palacios, A. y Romañach, J. (2006): El modelo de la diversidad. La Bioética y los Derechos Humanos como herramientas para alcanzar la plena dignidad en la diversidad funcional, España: Diversitas. 